\title{
Bullying Victimization and Life Satisfaction Among Rural Left-Behind Children in China: A Cross-Sectional Study
}

\begin{abstract}
Yide Yang ${ }^{1+}$, Chanjuan Zheng ${ }^{1+}$, Ming Xie ${ }^{1}$, Shuqian Yuan ${ }^{1}$, Yuan Zeng ${ }^{1}$, Meiling Zhou ${ }^{1}$, Shuzhen Huang ${ }^{1}$, Yulian Zhu ${ }^{2}$, Xiangli Ye ${ }^{1}$, Zhiyong Zou ${ }^{3 *}$, Ying Wang ${ }^{4 *}$ and Julien Steven Baker ${ }^{5}$

${ }^{1}$ Key Laboratory of Molecular Epidemiology of Hunan Province, School of Medicine, Hunan Normal University, Changsha, China, ${ }^{2}$ Hunan Preventive and Treatment Center for Occupational Diseases, Changsha, China, ${ }^{3}$ Institute of Child and Adolescent Health, School of Public Health, Peking University, Beijing, China, ${ }^{4}$ Department of Psychiatry, Renmin Hospital of Wuhan University, Wuhan, China, ${ }^{5}$ Department of Sport, Physical Education and Health, Centre for Health and Exercise Science Research, Hong Kong Baptist University, Hong Kong, China
\end{abstract}

OPEN ACCESS

Edited by:

Ziqiang Han

Shandong University, China

Reviewed by:

Hui Xiao,

University of Otago, New Zealand

Zepeng Gong,

University of Electronic Science and Technology of China, China

*Correspondence:

Zhiyong Zou

harveyzou2002@bjmu.edu.cn

Ying Wang

wangying@whu.edu.cn

tThese authors have contributed equally to this work and share first authorship

Specialty section:

This article was submitted to Children and Health,

a section of the journal

Frontiers in Pediatrics

Received: 12 March 2021 Accepted: 24 May 2021 Published: 30 July 2021

Citation:

Yang $Y$, Zheng $C$, Xie M, Yuan S, Zeng Y, Zhou M, Huang S, Zhu Y, Ye X, Zou Z, Wang Y and Baker JS (2021) Bullying Victimization and Life Satisfaction Among Rural Left-Behind Children in China: A Cross-Sectional

Study. Front. Pediatr. 9:671543. doi: 10.3389/fped.2021.671543
Objectives: This study aimed to evaluate the associations between bullying victimization and life satisfaction in primary school children and also investigate the interactive effects of left-behind status and bullying victimization on life satisfaction.

Materials and Methods: Bullying victimization was measured using the Chinese version of the revised Olweus Bully/Victim Questionnaire. Life satisfaction was assessed using the Multidimensional Students' Life Satisfaction Scale (MSLSS). Life satisfaction is composed of five domains, namely, family, school, friends, environment, and self-satisfaction. Left-behind status of rural children was defined as one or both their parents migrating to working in cities. The data were analyzed using Mann-Whitney $U$ tests, Chi-square tests, and multivariate linear and logistic regression analyses.

Results: A total of 810 primary school children were involved, of which $8.5 \%$ reported bullying victimization, and $44.3 \%$ were left-behind children (LBC). We found that bullying victimization was negatively associated with all domains of life satisfaction (all $p<0.05$ ). With further left-behind status-stratified analysis, we found that negative association between bullying victimization and friend satisfaction was more profound in the LBC group than in the non-LBC group $[b(S E)=-0.133$ (0.03) vs. -0.061 (0.026) for LBC and non-LBC, respectively, $p<0.05]$. When further interaction analysis was conducted, we identified interaction effects between left-behind status and bullying victimization on friend satisfaction ( $p_{\text {interaction }}=0.048$ ). Similar interaction effect between bullying victimization and left-behind status on school satisfaction was also found ( $\left.p_{\text {interaction }}=0.004\right)$.

Conclusions: Bullying victimization was associated with low life satisfaction (including lower family, friends, school, self, and environment satisfaction). There were significant interactions between left-behind status and bullying victimization on friend satisfaction, as well as school satisfaction. Left-behind status of children may exaggerate the impact of bullying victimization on friends/school satisfaction rating.

Keywords: bullying victimization, life satisfaction, primary school, interactive effects, left behind children 


\section{INTRODUCTION}

School bullying, including physical forms (e.g., kicking, hitting), verbal forms (e.g., teasing, called mean names, threatened), or psychological aggression (e.g., isolation or rumors), is a worldwide public health issue (1-4). According to a recent national representative study in China, the prevalence of school bullying victimization among primary school students (Grade 16 ) is the highest when compared with middle school (Grade 7-9) or high school students (Grade 11-12) (5). A further study in China showed that compared with high grade children (Grade 10 ), Grade 6 students have a 5.03-fold risk of being bullied (6). These findings indicate that bullying is likely to occur and is a significant concern for primary school students. Mounting evidence has demonstrated that bullying victimization increases the risk of negative and detrimental mental health problems, such as psychological distress, low life satisfaction, depression, and suicidality (7-10). These negative impacts are detrimental and progress into adulthood $(11,12)$.

Life satisfaction is a subjective assessment of life quality and is usually achieved by getting individual general needs, goals, or desires satisfied (13). If these basic but important needs or goals are not met or achieved, this usually results in unhappiness or contributes to further mental problems $(14,15)$. For school age students, their life satisfactions include different domains of life, namely, family, friends, school, self, and environment (16). Several studies have explored the association between bullying victimization and life satisfaction, demonstrating that bullying is associated with significantly lower life satisfaction (10, 17-19).

The left-behind children (LBC) phenomenon refers to the status of a child or adolescent with one or both their parents leaving their home or hometown for work for at least 6 months (20-23). The LBC phenomenon is highly prevalent in major labor export provinces, especially in central and western provinces (24). Hunan Province is a relatively deprived socioeconomic province, and the LBC phenomenon is quite common in Hunan Province. It has been estimated that there were 4.3511 million LBC in the rural area of Hunan Province according to a national survey conducted in 2010 (24). Also, a recent systematic review showed that 91 of 111 studies investigating health impacts of leftbehind status were conducted in China (20). LBC are vulnerable to many health problems, such as depressive symptoms (25), oral health problems $(26,27)$, and delayed growth (28). Notably, emotional, behavioral, and metal health problems in LBC have been comprehensively examined in different countries. Measures have included bullying victimization, life satisfaction, depression, and suicide attempts $(11,20,29-31)$. In previous studies, leftbehind status or experience was shown to be a moderator of association between children's or teachers' behavior and students' mental traits $(32,33)$. For example, a school-based health survey in China conducted in 2017 showed that the association between self-esteem and aggressive behavior was more profound in participants with left-behind experiences, and this study found significant interactions between left-behind experience and selfesteem on aggressive behaviors (32). No previous studies have examined the moderating role of left-behind status on the association between bullying victimization and life satisfaction.
In summary, bullying victimization is associated with significantly lower life satisfaction, and the left-behind status of children is likely to be a moderator in the association between bullying victimization and life satisfaction; in other words, there could be interaction effects between left-behind status and bullying victimization on life satisfaction and its different domains. Hunan Province is one of the provinces with the highest number of LBC in China. Bullying victimization and life satisfaction among LBC have been previously examined in Hunan Province. However, no previous studies have explored the interaction between bullying victimization and left-behind status in relation to life satisfaction in children, including family, friends, school, self, and environment satisfaction.

Based on the above discussion, we have proposed two hypotheses as follows: (1) bullying victimization is associated with lower life satisfaction, including the five domains (family, friends, school, self, and environment satisfaction) and (2) there are significant interactive effects between left-behind status and school bullying on life satisfaction (family, friends, school, self, and environment satisfaction).

To examine the hypothesis, we conducted a cross-sectional study on the children of Hunan Province, China, to verify the association of bullying victimization and life satisfaction. We also explored the interactive effects between left-behind status and school bullying on different domains of life satisfaction (family, friends, school, self, and environment satisfaction).

\section{MATERIALS AND METHODS}

\section{Location}

This present study was conducted in Hunan Province, one of Central China's most populated provinces, with 68.22 million residents and an area of $211,800 \mathrm{~km}^{2}$ in 2016 . Hunan Province exports large quantities of labor force to other coastal developed cities every year. The left-behind phenomenon is quite common in children, especially in rural or western areas of Hunan Province. According to a national survey in 2010, the number of LBC in rural Hunan Province is estimated to be 4.3511 million (24).

\section{Participants}

A cross-sectional study was conducted among primary school students in three different districts in western Hunan Province in July 2018 using convenience sampling. At first, a total of 820 primary school students and 93 junior high school students were investigated. The sample of the junior high school students was limited, so in the present study, we only involved primary school students. Among these 820 primary school children, 10 children's questionnaires were incomplete (no data of life satisfaction). Therefore, the final sample size in this study was 810 . The study was approved by the Research Ethical Review Committee Board of Hunan Normal University (2019-88). Written informed consent was obtained from all participants and their parents or other legal guardians prior to data collection.

Since the official announcement of the "Compulsory Education Law of the People's Republic of China” in April 1986, all children in China are required to receive a 9-year compulsory 
education in primary and junior middle school (primary school: from Grade 1 to 6 , middle school: from Grade 7 to 9). In addition, previous studies in China have found that compared with high school or middle school students, primary school students have a significantly higher risk of being bullied $(5,6)$. Therefore, we chose primary school students (Grade 1-6) to explore the associations between bullying victimization, left-behind status, and life satisfaction.

\section{Measurements \\ Bullying Victimization}

For bullying victimization, we used the Chinese version of the revised Bully/Victim Questionnaire developed by Dan Olweus (34). We asked the participants six questions to be answered on a 3 -point scale $(0=$ never, $1=$ sometimes, $2=$ often $)$ : in the past 30 days have you (1) been teased in a hurtful way; (2) been blackmailed; (3) been rejected or isolated by peers; (4) been threatened; (5) been hit, kicked, pushed, shoved around, or locked indoors; and (6) been made fun of due to your physical appearance (34). This questionnaire has proven to have good reliability and validity and has been used widely in China in previous studies $(29,35-37)$. The Cronbach $\alpha$ coefficient was 0.78 in the current study. Children reported at least one question of being bullied with the option of "often" in the past month being defined as being bullied as outlined in previous studies $(36,38)$.

\section{Left-Behind Status}

In this study, we used the definition of left-behind as defined in previous studies $(20,21,23)$. When one or both parents migrate from where the child lives and leaves behind the child to live alone or with grandparents or other relatives for at least 6 months, then, the child is categorized as LBC (21-23). For further analysis, we divided the subjects into two groups: LBC with one parent migration group and LBC with migration of both parents group.

\section{Multidimensional Students' Life Satisfaction Scale}

Life satisfaction was assessed using the Multidimensional Students' Life Satisfaction Scale (MSLSS) Chinese version, with a Cronbach $\alpha$ coefficient of 0.90 and a retest reliability of 0.869 obtained in previous studies $(39,40)$. The MSLSS has five subscales to measure five domains of life satisfaction: family, school, friends, environment, and self-satisfaction. The subscales have acceptable internal consistency and were validated in previous studies for children $(39,40)$. These are useful and widely used for the assessment of students' life satisfaction (16, 4143). The Cronbach's alpha value of MSLSS in the present study was 0.869 .

\section{Statistical Analysis}

The characteristics of quantitative variables are described as median and interquartile range (IQR) since the variables were not normally distributed and were categorical variables by number and percentages. Chi-square tests were used to compare the categorical variables between boys and girls, and independent-samples Mann-Whitney $U$ tests were used to compare the quantitative variable differences between boys and girls. The associations between bullying victimization and life satisfaction (including its domains: family, friends, school, self, environment satisfaction) were examined by multivariate linear regression analyses with adjustments for age, sex, and ethnicity. The association between left-behind status and bullying victimization was examined using univariate and multivariate logistic regression analyses with adjustments for age, sex, ethnicity, education level of the father, and education level of the mother. Stratified analyses of the left-behind status of association between bullying and life satisfaction (including its domains: family, friends, school, self, environment satisfaction) were conducted, and then the interactions were tested using a multivariate general linear model including the interaction term with age, sex, and ethnicity as covariates. In the stratified analyses in our study, the interaction was defined as a different effect size in the subgroups, but the interaction was significant $\left(p_{\text {interaction }}<0.05\right)(44)$. For the significant interaction effects between left-behind status and bullying victimization, the adjusted means and standard errors of friend and school satisfaction score in different groups were obtained using general linear model with age, ethnicity, and sex adjusted (presented in the figure) (45-47). With regard to missing data in the present study, among these 820 primary school children, 10 children's questionnaires were incomplete (no data of life satisfaction). For the multivariate analysis, missing data were excluded for the statistical analysis (9). All statistical analyses were conducted using IBM SPSS 20.0 for Windows (SPSS Inc., Chicago, IL, USA). $p<0.05$ was considered statistically significant.

\section{RESULTS}

\section{General Characteristics}

A total of 810 children were involved in the present study; the median (IQR) age was $9(7,10)$ years, the median (IQR) bullying score was $0(0,2)$, and the median (IQR) MSLSS score was 24.03 $(21.78,25.98)$. There were 454 boys $(56.0 \%)$ and 356 girls $(44 \%)$. The prevalence of school bullying was $8.5 \%$ ( 8.8 vs. $8.1 \%$ for boys and girls, respectively). For the specific bullying victimization behaviors, no significant differences were observed between the boys and girls $(p>0.05)$. Boys reported significantly higher selfsatisfaction than girls (median score was 4.86 vs. $4.57, p=0.042$ ). The prevalence of LBC was $44.3 \%$ ( 44.1 and $44.7 \%$ for boys and girls, respectively). Among the LBC, 179 children had only one parent migrated for work, and 180 children had both parents migrated (Table 1).

\section{Association Between Bullying Victimization and Different Domains of Life Satisfaction}

For the associations between bullying victimization and different domains of life satisfaction, the results are outlined in Table 2. With adjustments for potential covariates (age, ethnicity, and sex), bullying victimization was significantly associated with lower family satisfaction $(b=-0.109, \mathrm{SE}=0.026, p<0.001)$, friend satisfaction $(b=-0.091, \mathrm{SE}=0.020, p<0.001)$, school satisfaction $(b=-0.095, \mathrm{SE}=0.021, p<0.001)$, environment satisfaction $(b=-0.065, \mathrm{SE}=0.022, p=0.004)$, self-satisfaction $(b=-0.076, \mathrm{SE}=0.025, p=0.003)$, and the total MSLSS $(\mathrm{b}=$ $-0.081, \mathrm{SE}=0.017 p<0.001)$. 
TABLE 1 | The general characteristics of the study population.

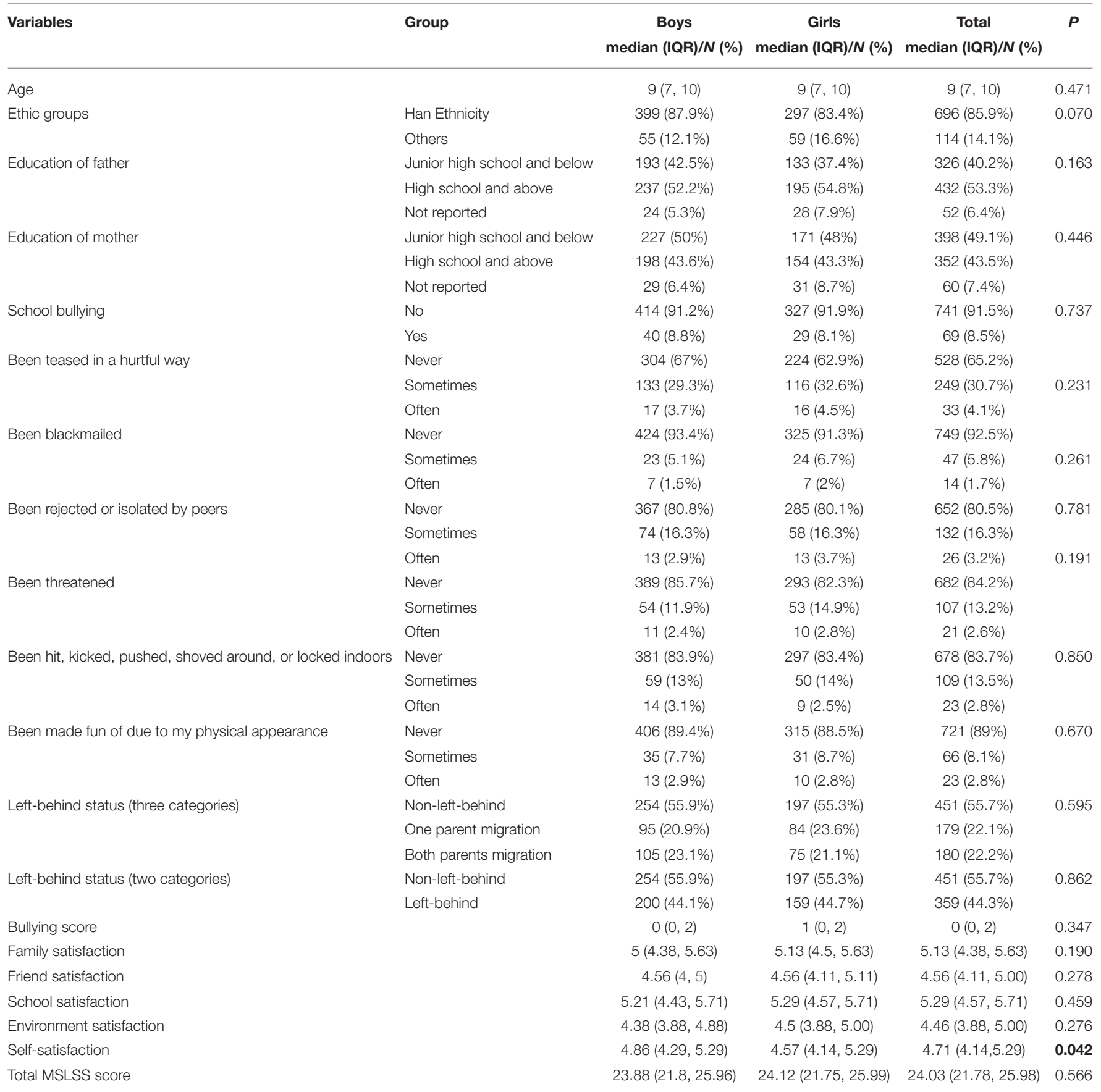

IQR, interquartile range; MSLSS, multidimensional students' life satisfaction scale. All significant results were marked in bold.

\section{Interaction Effect of Left-Behind Status and Bullying Victimization on Life Satisfaction}

When stratified by left-behind status, we found that the associations between bullying victimization and some life satisfaction domains varied substantially in the LBC and non-LBC groups (Table 3). For the family, environment, and self-satisfaction domains, bullying victimization, no significant interaction effects between left-behind status and bullying victimization on their satisfaction score were noted ( $p_{\text {interaction }}$ $>0.05)$.

For friend satisfaction domain, in the non-LBC group, bullying victimization was negatively associated with the friend satisfaction score; compared with the no bullying group, those with bullying victimization had 0.061 lower score in the Ln 
value of friend satisfaction score than in non-LBC $(b=-0.061$, $\mathrm{SE}=0.026, p=0.021)$. While in the LBC group, bullying victimization was associated with friend satisfaction score with a more profound effect size of $-0.133(\mathrm{SE}=0.03, p<0.001)$; this means that the bullying victimization group had 0.133 lower score in the Ln value of school satisfaction score in LBC. The adjusted mean of Ln friend satisfaction score with standard error by left-behind status and bullying victimization is shown in Figure 1A. With further interaction analysis, we found that there was a significant interaction between left-behind status and bullying victimization on friend satisfaction $\left(p_{\text {interaction }}=0.048\right)$.

For the school domain, a similar significant interaction effect between left-behind status and bullying victimization on school

TABLE 2 | Association between bullying victimization and different aspects of children's life satisfaction.

\begin{tabular}{llll}
\hline Life satisfaction scores & B & SE & $P$ \\
\hline Ln family satisfaction score & -0.109 & 0.026 & $<0.001$ \\
Ln friend satisfaction score & -0.091 & 0.020 & $<0.001$ \\
Ln school satisfaction score & -0.095 & 0.022 & $<0.001$ \\
Ln environment satisfaction score & -0.065 & 0.022 & 0.004 \\
Ln self-satisfaction score & -0.076 & 0.025 & 0.003 \\
Ln total MSLSS score & -0.081 & 0.017 & $<0.001$
\end{tabular}

Adjustment of age, ethnicity, and sex. Since the scores are not normally distributed, the scores were log transformed for analysis. satisfaction was found ( $p_{\text {interaction }}=0.004$ ). In the non-LBC group, bullying victimization was not associated with significant school satisfaction $(b=-0.041, \mathrm{SE}=0.031, p=0.188)$. While in the LBC group, bullying victimization was associated with a significant lower level of school satisfaction with an effect size of -0.167 ( $\mathrm{SE}=0.032, p<0.001)$, which means that the bullying victimization group had 0.167 lower score in the $\mathrm{Ln}$ value of school satisfaction score in LBC. The adjusted mean of Ln school satisfaction score with standard error by left-behind status and bullying victimization is shown in Figure 1B.

\section{DISCUSSION}

Our study found that bullying victimization was negatively associated with life satisfaction (including family, friends, school, environment, and self-satisfaction); in addition, we found that there were interaction effects between left-behind status and school bullying on friend satisfaction, as well as school satisfaction. Left-behind status in children may exaggerate the impact of being bullied associated with different life satisfaction aspects. To the best of our knowledge, this is the first study to explore the interaction effects of bully victimization and leftbehind status on life satisfaction. Findings from our study could help develop better strategies for psychological interventions among children suffering bullying victimization, especially for those who are LBC.

\begin{tabular}{|c|c|c|c|c|c|c|}
\hline \multirow[t]{3}{*}{ Family score } & Non-LBC & No & $5.13(4.38,5.75)$ & $-0.119(0.037)$ & 0.001 & 0.737 \\
\hline & & Yes & $4.81(3.88,5.38)$ & & & \\
\hline & LBC & No & $5.06(4.50,5.50)$ & $-0.101(0.035)$ & 0.004 & \\
\hline & & Yes & $4.49(4.00,4.89)$ & & & \\
\hline & LBC & No & $4.56(4.11,5.11)$ & $-0.133(0.03)$ & $<0.001$ & \\
\hline & & Yes & $4.22(3.33,4.78)$ & & & \\
\hline \multirow[t]{2}{*}{ School score } & Non-LBC & No & $5.14(4.43,5.71)$ & $-0.041(0.031)$ & 0.188 & 0.004 \\
\hline & & Yes & $5.03(4.00,5.71)$ & & & \\
\hline & & Yes & $4.25(3.88,4.75)$ & & & \\
\hline & LBC & No & $4.50(3.88,5.00)$ & $-0.086(0.034)$ & 0.013 & \\
\hline & & Yes & $4.13(3.63,4.75)$ & & & \\
\hline \multirow[t]{4}{*}{ Self-score } & Non-LBC & No & $4.86(4.29,5.43)$ & $-0.068(0.036)$ & 0.060 & 0.561 \\
\hline & & Yes & $4.71(4.00,5.29)$ & & & \\
\hline & LBC & No & $4.71(4.14,5.29)$ & $-0.089(0.035)$ & 0.013 & \\
\hline & & Yes & $4.29(3.43,5.14)$ & & & \\
\hline
\end{tabular}

Adjustment of age, ethnicity, and sex. Since the scores are not normally distributed, scores were log transformed for analysis. SE, standard error; LBC, left-behind children; MSLSS, multidimensional students' life satisfaction scale. 


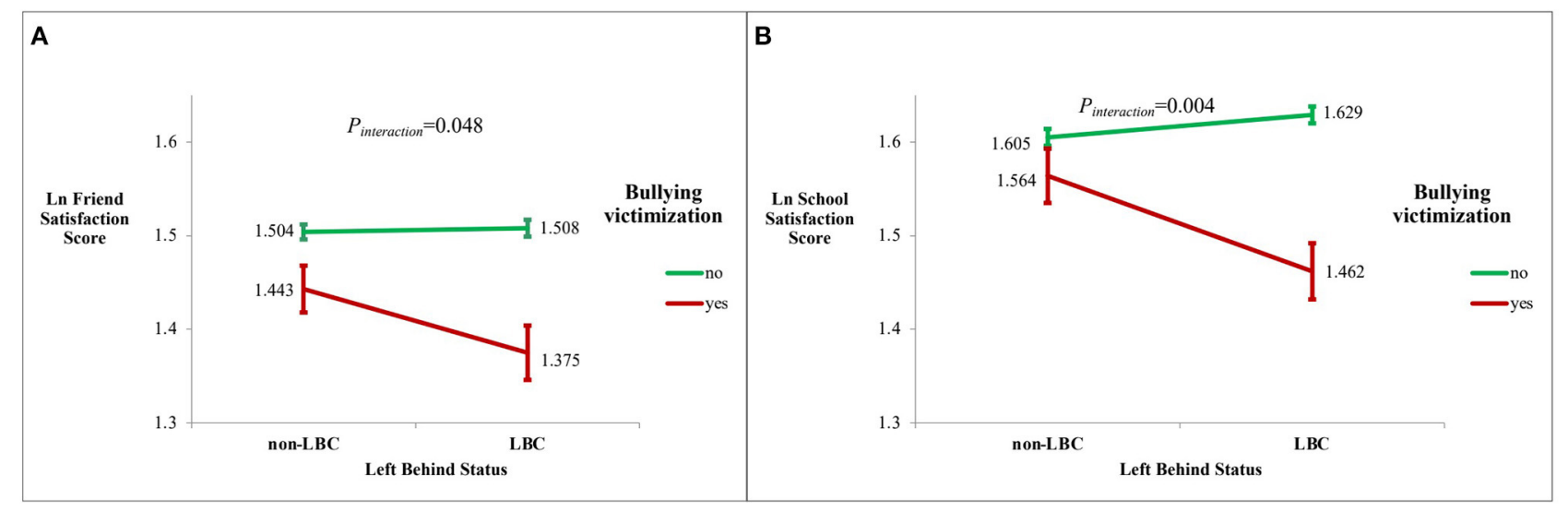

FIGURE 1 | Adjusted means and standard errors of Ln friend and school satisfaction scores stratified by left-behind status and bullying victimization. LBC: left-behind children. Non-LBC: non-left-behind children. Adjusted means and standard errors were estimated under general linear regression model with adjustment for age, ethnicity, and sex. (A) Friend satisfaction score and (B) school satisfaction score.

Consistent with previous correlational studies (10, 48-52), we verified the negative impact of bullying victimization on different domains or the total score of life satisfaction. The study by Moore et al. on USA adolescents reported pervasive relationships between experiences of bullying and life satisfaction across a variety of domains of satisfaction (48). Also, a Spanish study showed that bullying victimization was associated with specific domains of life satisfaction (including school, family, friends, and self-satisfaction; environment satisfaction was not examined) (49). The studies by Blood and colleagues (52) and Rezapour et al. (51) both reported negative association between bullying victim and total life satisfaction. Slightly different with our finding, Bilic et al. found that children exposed to classic or cyber bullying showed less satisfaction with family and friends, but not significantly associated with school satisfaction in rural and urban areas of Croatia (19); this discrepancy may be due to the different ethnicities or different sample sizes $(n=562$ and 810 for the study by Bilic and our study, respectively). The underlying reasons of association between bullying victimization and life satisfaction are not clear now, but there are some possible speculations. Firstly, because being bullied may lead to many negative mental problems, such as depression, social anxiety, and even suicide attempts $(6,53-55)$, these outcomes of being bullied substantially decrease the level of perceived life satisfaction. Secondly, low self-esteem could be a possible mediator for the association between school life satisfaction and being bullied (4). Additionally, the detrimental impact of experience of being bullied in primary school on psychosocial health (including life satisfaction) lasts into adulthood (12). So, it is important to make efforts to prevent bullying victimization and improve individual life satisfaction.

Notably, our study also identified significant interaction effects between left-behind status and bullying victimization on friend satisfaction, as well as school satisfaction. These findings suggest that left-behind status may exaggerate the negative impact of being bullied on friends or school satisfaction. The relationship with peers or friends in childhood is very important; it is reasonable and logical to expect that bullying victimization would affect friend satisfaction (19). Considering the absence of parents' support for LBC, experience of bullying victimization might lead to distrust, sense of insecurity or vulnerability, and subsequently result in lower friends or school satisfaction. So, if the children are suffering from bullying victimization, especially for LBC, efforts for providing enough peer and teacher support could be beneficial for improving their satisfaction or hope in life $(56,57)$. In addition, the direction of the associations between bullying victimization and life satisfaction requires further investigation. A recent study in China suggested that bullying victimization of LBC could be affected by school life satisfaction (4); so among LBC, the association between bullying victimization and life satisfaction could be bidirectional. Therefore, future in-depth qualitative interviews or intervention studies should be warranted to improve our understanding of this relationship. Although no previous studies have investigated the interaction between bullying victimization and left-behind status on life satisfaction, the study by Barzilay showed that there were significant interaction effects between bullying victimization and parental support and the risk of suicide attempts (54). Leftbehind status or parent-child separation is related to a lower level of parent support (58). Therefore, the interaction between left-behind status and bullying victimization on friends/school satisfaction might be due to the low parent support in the LBC. However, the underlying mechanisms need further scientific investigation to confirm this interaction effect. Effective measures and strategies from different stakeholders (including the individual, peers, family, and school) should be implemented to improve these domains of life satisfaction in this specific vulnerable population.

There are some limitations in our study. Firstly, the present study is a cross-sectional study that could only provide 
associations but not causal inference. Future studies should be longitudinal or even interventions that should be conducted to verify and better understand the associations outlined here. Secondly, this study was only conducted in three districts of Hunan Province by convenience sampling, which may limit generalizations to other areas of China. Thirdly, the current study only involved primary school students; therefore, the results obtained could not be generalizable to children of other ages or migrant status.

\section{CONCLUSIONS}

This study indicates that bullying victimization was associated with lower levels of life satisfaction across all domains of life (family, friends, school, self, and environment satisfaction), and left-behind status could interact with bullying victimization to have a negative impact on different domains of life satisfaction (including friends and school satisfaction). It appears that leftbehind status in children may exaggerate the impact of bullying victimization on friend satisfaction, as well as school satisfaction.

\section{DATA AVAILABILITY STATEMENT}

The raw data supporting the conclusions of this article will be made available by the authors, without undue reservation.

\section{ETHICS STATEMENT}

The studies involving human participants were reviewed and approved by Review Board of Hunan Normal University.

\section{REFERENCES}

1. Olweus D. School bullying: development and some important challenges. Annu Rev Clin Psychol. (2013) 9:75180. doi: 10.1146/annurev-clinpsy-050212-185516

2. Nansel TR, Overpeck M, Pilla RS, Ruan WJ, Simons-Morton B, Scheidt P. Bullying behaviors among US youth: prevalence and association with psychosocial adjustment. JAMA. (2001) 285:2094-100. doi: 10.1001/jama.285.16.2094

3. Janssen I, Craig WM, Boyce WF, Pickett W. Associations between overweight and obesity with bullying behaviors in school-aged children. Pediatrics. (2004) 113:1187-94. doi: 10.1542/peds.113.5.1187

4. Yan H, Chen J, Huang J. School bullying among left-behind children: the efficacy of art therapy on reducing bullying victimization. Front Psychiatry. (2019) 10:40. doi: 10.3389/fpsyt.2019.00040

5. Han Z, Zhang G, Zhang H. School bullying in urban china: prevalence and correlation with school climate. Int J Environ Res Public Health. (2017) 14:1116. doi: 10.3390/ijerph14101116

6. Zhang H, Zhou H, Tao T. Bullying behaviors and psychosocial adjustment among school-aged children in China. J Interpers Violence. (2019) 34:236375. doi: $10.1177 / 0886260518780777$

7. Han Z, Fu M, Liu C, Guo J. Bullying and suicidality in urban chinese youth: the role of teacher-student relationships. Cyberpsychol Behav Soc Netw. (2018) 21:287-93. doi: 10.1089/cyber.2017.0484

8. Zhang X, Han Z, Ba Z. Cyberbullying involvement and psychological distress among chinese adolescents: the moderating effects of family cohesion and school cohesion. Int J Environ Res Public Health. (2020) 17:8938. doi: 10.3390/ijerph17238938
Written informed consent to participate in this study was provided by the participants' legal guardian/next of kin.

\section{AUTHOR CONTRIBUTIONS}

YY, ZZ, and CZ conceived and designed the study. YY, CZ, MX, SY, MZ, SH, and YZe contributed for literature research, data collection, data analysis, manuscript preparation, and manuscript revision. YZh, XY, YW, JSB, and ZZ contributed for literature search and manuscript revision. All authors listed have made a substantial, direct and intellectual contribution to the work, and approved it for publication.

\section{FUNDING}

This study was supported by the National Natural Science Foundation of China (81903336), Hunan Provincial Natural Science Foundation of China (2019JJ50376), Scientific Research Fund of Hunan Provincial Education Department (18C0072), Scientific Research Fund of Hunan Provincial Education Department (18A028), National Natural Science Foundation of China (81773454), and The Hunan Provincial Natural Science Foundation of China (2020JJ5386, CZ).

\section{ACKNOWLEDGMENTS}

The authors are grateful to all the children who participated in this study and the teachers who contributed to this study.
9. Hong L, Guo L, Wu H, Li P, Xu Y, Gao X, et al. Bullying, depression, and suicidal ideation among adolescents in the fujian province of China: a cross-sectional study. Medicine. (2016) 95:e2530. doi: 10.1097/MD.0000000000002530

10. Ramos Salazar L. Cyberbullying victimization as a predictor of cyberbullying perpetration, body image dissatisfaction, healthy eating and dieting behaviors, and life satisfaction. J Interpers Violence. (2021) 36:35480. doi: $10.1177 / 0886260517725737$

11. Henry KL, Lovegrove PJ, Steger MF, Chen PY, Cigularov KP, Tomazic RG. The potential role of meaning in life in the relationship between bullying victimization and suicidal ideation. J Youth Adolesc. (2014) 43:22132. doi: 10.1007/s10964-013-9960-2

12. Blood GW, Blood IM. Long-term consequences of childhood bullying in adults who stutter: social anxiety, fear of negative evaluation, selfesteem, and satisfaction with life. J Fluency Disord. (2016) 50:7284. doi: 10.1016/j.jfludis.2016.10.002

13. Antaramian SP, Huebner ES, Valois RF. Adolescent life satisfaction. Applied Psychology. (2008) 57:112-26. doi: 10.1111/j.1464-0597.2008.00357.x

14. Suldo SM, Huebner ES. The role of life satisfaction in the relationship between authoritative parenting dimensions and adolescent problem behavior. Soc Indic Res. (2004) 66:165-95. doi: 10.1007/978-1-4020-2312-5_9

15. Hui H, Hong JS, Espelage DL. Understanding factors associated with bullying and peer victimization in chinese schools within ecological contexts. J Child Fam Stud. (2013) 22:881-92. doi: 10.1007/s10826-0129647-4

16. Schnettler B, Orellana L, Lobos G, Miranda H, Sepulveda J, Etchebarne S, et al. Relationship between the domains of the Multidimensional Students' Life Satisfaction Scale, satisfaction with 
food-related life and happiness in university students. Nutr Hosp. (2015) 31:2752-63. doi: 10.3305/nh.2015.31.6.8593

17. Arnarsson A, Nygren J, Nyholm M, Torsheim T, Augustine L, Bjereld Y, et al. Cyberbullying and traditional bullying among Nordic adolescents and their impact on life satisfaction. Scand J Public Health. (2020) 48:50210. doi: $10.1177 / 1403494818817411$

18. Przybylski AK, Bowes L. Cyberbullying and adolescent well-being in England: a population-based cross-sectional study. Lancet Child Adolesc Health. (2017) 1:19-26. doi: 10.1016/S2352-4642(17)30011-1

19. Bilic V, Flander GB, Rafajac B. Life satisfaction and school performance of children exposed to classic and cyber peer bullying. Coll Antropol. (2014) 38:21-9.

20. Fellmeth G, Rose-Clarke K, Zhao C, Busert LK, Zheng Y, Massazza A et al. Health impacts of parental migration on left-behind children and adolescents: a systematic review and meta-analysis. Lancet. (2018) 392:256782. doi: 10.1016/S0140-6736(18)32558-3

21. Zhao X, Chen J, Chen MC, Lv XL, Jiang YH, Sun YH. Left-behind children in rural China experience higher levels of anxiety and poorer living conditions. Acta Paediatr. (2014) 103:665-70. doi: 10.1111/apa.12602

22. Zhang X, Li M, Guo L, Zhu Y. Community-based family workshop intervention improved the social adaptation of left-behind children in rural China. Front Public Health. (2020) 8:506191. doi: 10.3389/fpubh.2020.506191

23. Duan C, Yang G. The left-behind children in rual China. Popul J. (2008) 32:1525. [in Chinese].

24. Duan C, Lv L, Guo j, Z W. Survival and development of left-behind children in rural China: based on the analysis of sixth census data. Popul J. (2013) 35:3748. [in Chinese].

25. Tan M, Chen M, Li J, He X, Jiang Z, Tan H, et al. Depressive symptoms and associated factors among left-behind children in China: a cross-sectional study. BMC Public Health. (2018) 18:1059. doi: 10.1186/s12889-018-5963-y

26. Su H, Zhang Y, Qian W, Shi H. Impact of behavioural factors and living conditions on dental caries among pupils from shanghai and jiangxi province in china: a school-based cross-sectional study. Oral Health Prev Dent. (2019) 17:557-65.

27. Qiu R, Li Y, Malla M, Yao J, Mo D, Dhakal N, et al. Impact of parental migration on oral health outcomes of left-behind schoolaged children in Luchuan, southern China. BMC Oral Health. (2018) 18:207. doi: 10.1186/s12903-018-0683-3

28. Zhang N, Becares L, Chandola T. Does the timing of parental migration matter for child growth? A life course study on left-behind children in rural China. BMC Public Health. (2015) 15:966. doi: 10.1186/s12889-015-2296-y

29. Yan L, Zhu Q, Tu X, Zuo X, Yu C, Lou C, et al. Bullying victimization and child sexual abuse among left-behind and non-left-behind children in China. PeerJ. (2018) 6:e4865. doi: 10.7717/peerj.4865

30. Zhao J, Li Q, Wang L, Lin L, Zhang W. Latent profile analysis of left-behind adolescents' psychosocial adaptation in rural China. J Youth Adolesc. (2019) 48:1146-60. doi: 10.1007/s10964-019-00989-1

31. Adhikari R, Jampaklay A, Chamratrithirong A, Richter K, Pattaravanich $\mathrm{U}$, Vapattanawong $\mathrm{P}$. The impact of parental migration on the mental health of children left behind. J Immigr Minor Health. (2014) 16:7819. doi: 10.1007/s10903-013-9809-5

32. Yu BL, Li J, Liu W, Huang SH, Cao XJ. The effect of left-behind experience and self-esteem on aggressive behavior in young adults in china: a crosssectional study. J Interpers Violence. (2020). doi: 10.1177/0886260520922373. [Epub ahead of print].

33. Li W, Gao WY, Fu WD. When does teacher support reduce depression in students? the moderating role of students' status as left-behind children. Front Psychol. (2021) 12:608359. doi: 10.3389/fpsyg.2021.608359

34. Olweus D. The Revised Olweus Bully/Victim Questionnaire. Bergen, Norway: Research Center for Health Promotion; University of Bergen (1996).

35. Zhang W, Wu J, KJ. Revision of Chinese Version of Olweus child bullying questionnaire. Psychol Dev Educ. (1999) 2:7-11+37.

36. Zhou Y, Guo L, Lu CY, Deng JX, He Y, Huang JH, et al. Bullying as a risk for poor sleep quality among high school students in China. PLoS ONE. (2015) 10:e0121602. doi: 10.1371/journal.pone.0121602

37. Gong Z, Han Z, Zhang H, Zhang G. Weight status and school bullying experiences in urban china: the difference between boys and girls. J Interpers Violence. (2020) 35:2663-86. doi: 10.1177/0886260519880170
38. Guo QZ, Ma WJ, Nie SP, Xu YJ, Xu HF, Zhang YR. Relationships between weight status and bullying victimization among school-aged adolescents in Guangdong Province of China. Biomed Environ Sci. (2010) 23:10812. doi: $10.1016 / \mathrm{S} 0895-3988(10) 60039-6$

39. Li-li T, L W. Test of the Chinese version of multidimensional students' life satisfaction scale. Chin Ment Health J. (2005) 19:301-3. [in Chinese].

40. ES H. Preliminary development and validation of a multidimensional life satisfaction scale for children. Psychol Assess. (1994) 6:149158. doi: 10.1037/1040-3590.6.2.149

41. Veronese G, Pepe A, Almurnak F, Jaradah A, Hamdouna H. Quality of life, primary traumatisation, and positive and negative affects in primary school students in the Gaza Strip. Lancet. (2018) 391 (Suppl 2):S14. doi: 10.1016/S0140-6736(18)30380-5

42. Xing XY, Tao FB, Hao JH, Xu SJ, Su PY, Huang ZH. [Study on the schoolrelated-factors of attempted suicide among rural middle school students]. Chin J Epidemiol. (2009) 30:21-5. [in Chinese].

43. Su PY, Tao FB, Sun Y, Huang K, Zhu P, Cheng XL. [Psychological well-being among adolescents of parents living with AIDS or HIV]. Chin J Epidemiol. (2007) 28:562-66.

44. Dempfle A, Scherag A, Hein R, Beckmann L, Chang-Claude J, Schafer H. Gene-environment interactions for complex traits: definitions, methodological requirements and challenges. Eur J Hum Genet. (2008) 16:1164-72. doi: 10.1038/ejhg.2008.106

45. Holmbeck GN. Post-hoc probing of significant moderational and mediational effects in studies of pediatric populations. J Pediatr Psychol. (2002) 27:8796. doi: 10.1093/jpepsy/27.1.87

46. Preacher KJ, Curran PJ, Bauer DJ. Computational tools for probing interactions in multiple linear regression, multilevel modeling, and latent curve analysis. J Educ Behav Stat. (2006) 31:437-48. doi: 10.3102/10769986031004437

47. Shadel WG, Tharp-Taylor S, Fryer CS. Exposure to cigarette advertising and adolescents' intentions to smoke: the moderating role of the developing self-concept. J Pediatr Psychol. (2008) 33:751-60. doi: 10.1093/jpepsy/jsn025

48. Moore PM, Huebner ES, Hills KJ. Electronic bullying and victimization and life satisfaction in middle school students. Soc Indic Res. (2012) 107:42947. doi: 10.1007/s11205-011-9856-Z

49. Navarro R, Ruiz-Oliva R, Larrañaga E, Yubero S. The impact of cyberbullying and social bullying on optimism, global and school-related happiness and life satisfaction among 10-12-year-old schoolchildren. Appl Res Qual Life. (2015) 10:15-36. doi: 10.1007/s11482-013-9292-0

50. Serra-Negra JM, Paiva SM, Bendo CB, Fulgencio LB, Lage CF, Correa-Faria P, et al. Verbal school bullying and life satisfaction among Brazilian adolescents: profiles of the aggressor and the victim. Compr Psychiatry. (2015) 57:1329. doi: 10.1016/j.comppsych.2014.11.004

51. Rezapour M, Khanjani N, Soori H. The types of bullying behaviors and its association with general life satisfaction and self-rated health among iranian pupils. J Res Health Sci. (2019) 19:e00436.

52. Blood GW, Blood IM, Tramontana GM, Sylvia AJ, Boyle MP, Motzko GR. Self-reported experience of bullying of students who stutter: relations with life satisfaction, life orientation, and self-esteem. Percept Mot Skills. (2011) 113:353-64. doi: 10.2466/07.10.15.17.PMS.113.5.3 53-364

53. Hinduja S, Patchin JW. Bullying, cyberbullying, and suicide. Arch Suicide Res. (2010) 14:206-21. doi: 10.1080/13811118.2010.4 94133

54. Barzilay S, Brunstein Klomek A, Apter A, Carli V, Wasserman C, Hadlaczky G, et al. Bullying victimization and suicide ideation and behavior among adolescents in Europe: a 10-country study. J Adolesc Health. (2017) 61:179-86. doi: 10.1016/j.jadohealth.2017. 02.002

55. Zhang H, Chi P, Long H, Ren X. Bullying victimization and depression among left-behind children in rural China: roles of self-compassion and hope. Child Abuse Negl. (2019) 96:104072. doi: 10.1016/j.chiabu.2019.1 04072

56. Flaspohler PD, Elfstrom JL, Van De Rzee KL, Sink HE, Birchmeier Z. Stand by me: the effects of peer and teacher support in mitigating the impact of bullying on quality of life. Psychol Sch. (2010) 46:636-49. doi: 10.1002/pits. 20404 
57. You S, Furlong MJ, Felix E, Sharkey JD, Green JG. Relations among school connectedness, hope, life satisfaction, and bully victimization. Psychol Sch. (2010) 45:446-60. doi: 10.1002/pits. 20308

58. Humphreys KL. Future directions in the study and treatment of parent-child separation. $J$ Clin Child Adolesc Psychol. (2019) 48:166-78. doi: 10.1080/15374416.2018.15 34209

Conflict of Interest: The authors declare that the research was conducted in the absence of any commercial or financial relationships that could be construed as a potential conflict of interest.
Publisher's Note: All claims expressed in this article are solely those of the authors and do not necessarily represent those of their affiliated organizations, or those of the publisher, the editors and the reviewers. Any product that may be evaluated in this article, or claim that may be made by its manufacturer, is not guaranteed or endorsed by the publisher.

Copyright () 2021 Yang, Zheng, Xie, Yuan, Zeng, Zhou, Huang, Zhu, Ye, Zou, Wang and Baker. This is an open-access article distributed under the terms of the Creative Commons Attribution License (CC BY). The use, distribution or reproduction in other forums is permitted, provided the original author(s) and the copyright owner(s) are credited and that the original publication in this journal is cited, in accordance with accepted academic practice. No use, distribution or reproduction is permitted which does not comply with these terms. 